\title{
Peroxynitrite Activity of Hemin-Functionalized Reduced Graphene Oxide
}

\author{
Raluca Oprea \\ Institut de Recherche Interdisciplinaire (IRI, USR 3078) \\ Serban F. Peteu \\ National Institute for R\&D in Chemistry and Petrochemistry,, sfpeteu@umich.edu \\ Palaniappan Subramanian \\ Institut de Recherche Interdisciplinaire (IRI, USR 3078) \\ Wang Qi \\ Institut de Recherche Interdisciplinaire (IRI, USR 3078) \\ Emmanualle Pichonat \\ Institute of Electronics, Microelectronics and Nanotechnology (IEMN)
}

See next page for additional authors

Follow this and additional works at: https://engagedscholarship.csuohio.edu/scichem_facpub

Part of the Chemistry Commons

How does access to this work benefit you? Let us know!

\section{Recommended Citation}

Oprea, Raluca; Peteu, Serban F.; Subramanian, Palaniappan; Qi, Wang; Pichonat, Emmanualle; Happy, Henri; Bayachou, Mekki; Boukherroub, Rabah; and Szunerits, Sabine, "Peroxynitrite Activity of HeminFunctionalized Reduced Graphene Oxide" (2013). Chemistry Faculty Publications. 322.

https://engagedscholarship.csuohio.edu/scichem_facpub/322

This Article is brought to you for free and open access by the Chemistry Department at EngagedScholarship@CSU. It has been accepted for inclusion in Chemistry Faculty Publications by an authorized administrator of EngagedScholarship@CSU. For more information, please contact library.es@csuohio.edu. 


\section{Authors}

Raluca Oprea, Serban F. Peteu, Palaniappan Subramanian, Wang Qi, Emmanualle Pichonat, Henri Happy, Mekki Bayachou, Rabah Boukherroub, and Sabine Szunerits 


\title{
Peroxynitrite activity of hemin-functionalized reduced graphene oxide
}

\author{
Raluca Oprea, Serban F. Peteu Palaniappan Subramanian, Wang Qi, \\ Emmanuelle Pichonat, Henri Happy, Mekki Bayachou, Rabah Boukherroub \\ and Sabine Szunerits
}

Conducting interfaces modified with reduced graphene oxide ( $\mathrm{GGO}$ ) have shown improved electrochemical response for different analytes. The efficient formation of functionalized rGO based materials is thus of current interest for the development of sensitive and selective biosensors. Herein, we report a simple and environmentally friendly method for the formation of a hemin functionalized rGO hybrid nanomaterial that exhibits remarkable sensitivity to peroxynitrite (ONOO) in solution. The hemin functionalized rGO hybrid nanomaterial was formed by mixing an aqueous solution of graphene oxide (GO) with hemin and sonicating the suspension for $5 \mathrm{~h}$ at room temperature. In addition to playing a key role in biochemical and electrocatalytic reactions, hemin has been proven to be a good reducing agent for GO. The sensitivity of the peroxynitrite sensor is $\approx 7.5 \pm 1.5 \mathrm{nA} \mathrm{mM}{ }^{1}$ with a detection limit of $5 \pm 1.5 \mathrm{nM}$.

\section{Introduction}

Recent clinical evidence shows the reactive nitrogen and oxygen species (RNOS) to play a fundamental role in aging. In the case of aerobic cells, the RNOS are produced to maintain their integrity when challenged by unsafe environmental exposures such as mechanical stress, UV radiation, toxins in air or water, bacteria, or viruses. Peroxynitrite $\left(\mathrm{ONOO}^{-}\right)$, a highly reactive metabolite known to be a potent oxidative and nitrosative agent, is also being clinically ascertained to exert a variety of deleterious and cytotoxic effects in cells and tissues, both in vitro and in living organisms, ${ }^{\mathbf{1} 3}$ where $\mathrm{ONOO}^{-}$is typically formed by the diffusion-controlled reaction of superoxide ions $\left(\mathrm{O}_{2}{ }^{-}\right)$and nitric oxide (NO). ${ }^{4}$ As one can appreciate from the $\mathrm{ONOO}^{-}$detection methods aptly reviewed in the literature,${ }^{5}$ the quantification of peroxynitrite continues to be tremendously complicated, for a variety of intrinsic obstacles, including the inherent difficulties to accurately reproduce the true in vivo kinetics of PON in the model experiments, ${ }^{5,8}$ the potential of misinterpreting the $\mathrm{ONOO}^{-}$concentration "as determined", if the experimental conditions are not carefully optimized, ${ }^{\mathbf{4 , 5}}$ and the vast complexities of the in vivo real environment, as $\mathrm{ONOO}^{-}$typically interacts with more than one target per unit time, due to its high reactivity. ${ }^{8,9}$ All this amounts to the $\mathrm{ONOO}^{-}$quantification as being one of the significant challenges in (bio)analytical chemistry. The major challenge in the detection of peroxynitrite anions at physiological $\mathrm{pH}$ is its short half-life time $(\approx 1 \mathrm{~s}$ or less) and its complex reactivity. ${ }^{\mathbf{1 0 , 1 1}}$ Indeed, at physiological $\mathrm{pH}$, peroxynitrite undergoes two main degradation routes: protonation into its conjugated acid ONOOH $\left(\mathrm{p} K_{\mathrm{a}} \approx 6.8\right)$ followed by the formation of the very reactive radicals $\mathrm{NO}_{2}{ }^{\circ}$ and $\mathrm{OH}$ or follow-up reactions with $\mathrm{CO}_{2}$, thiols, metals, etc. ${ }^{\mathbf{1 0}}$ The detection and quantification of $\mathrm{ONOO}^{-}$is thus extremely difficult. The most widely used methods for peroxynitrite detection are fluorescence based techniques. ${ }^{12}{ }^{16}$ Studies on the biochemical roles of nitric oxide and superoxide ions using electrochemical detection methods proved to be great analytical techniques when it comes to real-time, label-free and direct measurements of these reactive species. ${ }^{17}{ }^{19}$ Nevertheless, very few examples of the direct detection of $\mathrm{ONOO}^{-}$by electrochemical techniques are reported in the literature. ${ }^{\mathbf{6 , 1 8 , 2 0} 25}$ Amatore and co-workers studied the electrochemical oxidation of peroxynitrite by steadystate and transient voltammetry using platinized carbon microelectrodes. ${ }^{\mathbf{1 8 , 2 0} 22}$ Xue et al. used manganese phthalocyanine-modified ultramicroelectrodes for the sensitive and selective detection of peroxynitrite anions, released from cultured neonatal myocardial cells induced by ischemia-reperfusion. ${ }^{23}$ Chemically modified platinum ultramicroelectrodes coated with manganese tetraaminophthalocyanine films were used by Bedioui and co-workers for the detection of $\mathrm{ONOO}^{-}$in alkaline 
solution $(\mathrm{pH}=10.2)$ where $\mathrm{ONOO}^{-}$is more stable. ${ }^{26}$ More recently, Peteu et al. showed that improved catalytic peroxynitrite activity can be achieved by depositing nanostructured poly(3,4-ethylenedioxythiophene)-metalloporphyrin films onto carbon fiber electrodes. ${ }^{4,27}$

Motivated by the reports on the electrocatalytic properties of manganese phthalocyanine or porphyrin-modified electrodes towards the detection and quantification of $\mathrm{ONOO}^{-},{ }^{28}$ we report herein on the use of reduced graphene oxide-hemin (rGO/ hemin) nanosheets for peroxynitrite detection. The twodimensional sheet-like rGO structure represents an interesting support for organic and inorganic catalysts with a large open surface area that is readily accessible to substrates/products with a small diffusion barrier. ${ }^{29,30}$ The potential of rGO to support organic molecules such as hemin and other porphyrin species through $\pi-\pi$ stacking interactions $s^{29,3135}$ makes this material of high interest for electrocatalytic applications. Indeed, hemin-graphene conjugates have shown to exhibit peroxidase activity $^{34}$ as well as peroxynitrite reduction activity. ${ }^{35}$ Surprisingly, the electrocatalytic properties of graphene-hemin hybrid materials for the detection of $\mathrm{ONOO}^{-}$have not been considered yet.

In this work, we report on the promising potential of an $\mathrm{rGO} /$ hemin modified glassy carbon interface for the sensitive electrocatalytic detection of peroxynitrite at neutral $\mathrm{pH}$. The rGO/ hemin matrix was formed by a facile and environmentally friendly approach based on the reduction of GO with hemin under ultrasonication at room temperature. This differs from $\mathrm{rGO} /$ hemin produced by other groups, where the reaction medium for the reduction of GO to rGO comprised ammonia or hydrazine. ${ }^{29,31} 34$ Reducing agents such as hydrazine need to be carefully handled due to their toxic nature; the formation of rGO by chemical reduction with less toxic agents is an important alternative. $\mathrm{We}^{3638}$ and others ${ }^{35,39,40}$ have shown that GO can be easily reduced using aromatic organic molecules such as dopamine and tetrathiafulvalene (TTF) under mild conditions. In the continuation of our ongoing work on non-covalent functionalization of rGO using strong electron donors, we investigated in this work whether hemin allows simultaneous reduction of and incorporation into GO nanosheets. The peroxynitrite activity of the novel hemin-reduced graphene oxide (rGO/hemin) was determined by chronoamperometry and voltammetry on a glassy carbon electrode (GCE) coated with the rGO/hemin composite material.

\section{Experimental}

\section{Materials}

Graphite powder ( $<20$ micron), hydrogen peroxide, sulfuric acid, iron protoporphyrin IX (hemin), dimethylsulfoxide (DMSO), potassium chloride (KCl), hydrazine monohydrate, ethanol, dimethyl formamide (DMF), methanol, dichloromethane, potassium ferricyanide $\left(\left[\mathrm{K}_{3} \mathrm{Fe}(\mathrm{CN})_{6}\right]\right)$, potassium ferrocyanide $\left(\left[\mathrm{K}_{4} \mathrm{Fe}(\mathrm{CN})_{6}\right]\right)$ and tin-doped indium oxide coated glass (ITO) (sheet resistivity 15-25 $\Omega \mathrm{cm}^{2}$ ) were purchased from Sigma Aldrich, St Louis, MO, US and used as received. 3-Morpholinosydnonimine (SIN-1) was purchased from Cayman Europe, Tallinn Estonia.
Phosphate buffer saline tablets (0.1 M, $\mathrm{pH}$ 7.4) were obtained from Gibco-Life Technologies, Grand Island, NY, US. Alumina $(0.05 \mu \mathrm{m})$ and diamond $(1 \mu \mathrm{m})$ polishing paste were purchased from ALS, Japan. Glassy carbon electrodes ( $5 \mathrm{~mm}$ in diameter), platinum wire counter electrodes and silver/silver chloride reference electrodes were obtained from Cambria Scientific, Llanelli, UK.

Preparation of graphene oxide (GO) and reduced graphene oxide (rGO) modified with hemin (rGO/hemin)

Graphene oxide (GO) was synthesized from graphite powder by a modified Hummers method ${ }^{\mathbf{4 1}}$ and the detailed experimental conditions are reported in ref. 42 . To $0.75 \mathrm{~mL}$ of a homogeneous GO suspension $\left(0.5 \mathrm{mg} \mathrm{mL}{ }^{-1}\right)$ in distilled water were added $0.75 \mathrm{~mL}$ of hemin $(10 \mathrm{mM})$ dissolved in DMF and ultrasonicated at $130 \mathrm{kHz}$ in a Fisher, Loughborough, Leicester, UK Transonic TI-H-10 ultrasonication bath for $5 \mathrm{~h}$ at $50{ }^{\circ} \mathrm{C}$. The resulting precipitate was separated from the supernatant by centrifugation ( $1 \mathrm{~h}$ at $14000 \mathrm{rpm}$ ), washed with water (twice) and then dried in an oven at $60{ }^{\circ} \mathrm{C}$ for $6 \mathrm{~h}$.

\section{Preparation of hydrazine reduced graphene oxide (rGO)}

In a typical procedure, hydrazine hydrate $(0.50 \mathrm{~mL}, 32.1 \mathrm{mM})$ was added to $5 \mathrm{~mL}$ of the yellow-brown GO aqueous suspension $\left(0.5 \mathrm{mg} \mathrm{mL}^{-1}\right)$ in a round bottom flask and heated in an oil bath at $100{ }^{\circ} \mathrm{C}$ for $24 \mathrm{~h}$. During this time, the reduced GO gradually precipitated out of the solution. The product was isolated by filtration over a polyvinylidene difluoride (PVDF) membrane with a $0.45 \mu \mathrm{m}$ pore size, washed copiously with water $(5 \times 20 \mathrm{~mL})$ and methanol $(5 \times 20 \mathrm{~mL})$, and dried in the oven at $60{ }^{\circ} \mathrm{C}$ for $6 \mathrm{~h}^{43}$

\section{Generation of peroxynitrite anion}

3-Morpholino-sydnonimine ( $\mathrm{SIN}-1$, stored at $\left.20{ }^{\circ} \mathrm{C}\right)^{\mathbf{4 4 , 4 5}}$ was used for the generation of peroxynitrite, with the concentration ratio (1/100) for $[\mathrm{PON}] /[\mathrm{SIN}-1]$ for each experiment; the stock solution was simply formed by mixing SIN-1 with deoxygenated PBS ( $\mathrm{pH}$ 7.4) at room temperature. For chronoamperometric tests a stock solution of $250 \mu \mathrm{M}$ SIN-1 in deoxygenated PBS was prepared and stored in leak-tight sealed vials. For cyclic voltammetric experiments the stock solution concentration was $1500 \mu \mathrm{M}$ SIN-1 in deoxygenated PBS. The ONOO $^{-}$concentration was assessed by UV/Vis measurements at $\lambda=302 \mathrm{~nm}\left(\varepsilon_{302}=\right.$ $1705 \mathrm{~mol}^{-1} \mathrm{~cm}^{-1}$ ) as described previously ${ }^{46}$ during the electrochemical experiment as well as after every electroanalytical test by adding a known aliquot of the stock solution to an oxygenated (or air-equilibrated) PBS buffer. In between experiments, solutions were typically kept on ice to minimize any spontaneous degradation.

\section{Electrode preparation}

Glassy carbon electrodes (GCEs) were polished with alumina and diamond paste and then sonicated in a mixture of ethanolacetone for $15 \mathrm{~min}$ before modification. GCE/rGO/hemin electrodes were prepared by casting a $20 \mu \mathrm{L}$ drop of $\mathrm{rGO} /$ hemin $\left(0.5 \mathrm{mg} \mathrm{mL}^{-1}\right.$ in DMF) followed by drying in an oven at $60^{\circ} \mathrm{C}$ for $30 \mathrm{~min}$. This was repeated five times. 
On the other hand, GCE/rGO electrodes were prepared by casting drops of $20 \mu \mathrm{L}$ of rGO $\left(0.5 \mathrm{mg} \mathrm{mL}^{-1}\right.$ in DMF) 5 times followed by drying in the oven at $60{ }^{\circ} \mathrm{C}$. This interface was then immersed in hemin ( $0.5 \mathrm{mM}$ in PBS) for $12 \mathrm{~h}$ followed by washing five times with PBS and water.

\section{Instrumentation}

X-ray photoelectron spectroscopy. X-ray photoelectron spectroscopy (XPS) experiments were performed in a PHI 5000 VersaProbe - Scanning ESCA Microprobe (ULVAC-PHI, Japan/ USA) instrument at a base pressure below $5 \times 10^{-9}$ mbar. Monochromatic $\mathrm{AlK}_{\alpha}$ radiation was used and the X-ray beam, focused to a diameter of $100 \mu \mathrm{m}$, was scanned on a $250 \times 250$ $\mu \mathrm{m}$ surface, at an operating power of $25 \mathrm{~W}(15 \mathrm{kV})$. Photoelectron survey spectra were acquired using a hemispherical analyzer at a pass energy of $117.4 \mathrm{eV}$ with a $0.4 \mathrm{eV}$ energy step. Core-level spectra were acquired at a pass energy of $23.5 \mathrm{eV}$ with a $0.1 \mathrm{eV}$ energy step. All spectra were acquired with $90^{\circ}$ between X-ray source and analyzer and with the use of low energy electrons and low energy argon ions for charge neutralization. After subtraction of the Shirleytype background, the core-level spectra were decomposed into their components with mixed Gaussian-Lorentzian (30:70) shape lines using the CasaXPS software. Quantification calculations were performed using sensitivity factors supplied by PHI.

Raman. Micro-Raman spectroscopy measurements were performed on a Horiba Jobin Yvon LabRam HR Micro-Raman system combined with a $473 \mathrm{~nm}$ laser diode as an excitation source. Visible light is focused by a $100 \times$ objective. The scattered light is collected by the same objective in the backscattering configuration, dispersed by a $1800 \mathrm{~mm}$ focal length monochromator and detected by a CCD.

UV/Vis measurements. Absorption spectra were recorded using a Jasco V-570 UV/VIS/NIR Spectrophotometer from Easton, Maryland, US.

Electrochemical measurements. Cyclic voltammetry (CV) and chronoamperometric (CA) experiments were performed using an Autolab PGSTAT 101 potentiostat (Eco Chimie, Utrecht, The Netherlands). The electrochemical cell consisted of a working electrode (GCE), $\mathrm{Ag} / \mathrm{AgCl}$ as the reference electrode, and platinum wire as the counter electrode. Cyclic voltammetric measurements were performed in PBS (0.1 M) under nitrogen or air at a scan rate $v=100 \mathrm{mV} \mathrm{s}^{-1}$. CA measurements were performed in PBS at an applied potential of $1.1 \mathrm{~V} v s$. $\mathrm{Ag} / \mathrm{AgCl}$. All electrochemical experiments were performed at room temperature controlled at $24 \pm 1{ }^{\circ} \mathrm{C}$.

\section{Results and discussion}

\section{Formation of rGO/hemin nanocomposite material}

We were interested in the development of a simple and environmentally friendly approach for the fabrication of an rGO-hemin hybrid material with the hope that such a material would have a good electrochemical response to peroxynitrite. Electron donating organic molecules such as dopamine and TTF have shown to allow simultaneous reduction of GO to $\mathrm{rGO}$ and insertion of organic aromatic molecules via $\pi-\pi$ stacking interactions..$^{37,38}$ Here we investigate whether hemin moieties would insert within the reduced GO nanosheets being formed under ultrasonication (Fig. 1).

To illustrate the formation of rGO at neutral $\mathrm{pH}$ in the presence of hemin and the simultaneous incorporation of hemin into the formed rGO matrix, we used X-ray photoelectron spectroscopy (XPS) analysis to identify the chemical changes that have occurred on the GO surface (Fig. 2). Deconvolution of the C1s spectrum of GO (Fig. 2A) clearly indicates the extensive degree of oxidation. The spectrum can be deconvoluted into four peaks with binding energies at about 283.8, 284.7, 286.7 and $287.9 \mathrm{eV}$ assigned to $\mathrm{sp}^{2}$-hybridized carbon, $\mathrm{C}-\mathrm{H} / \mathrm{C}-\mathrm{C}, \mathrm{C}-\mathrm{O}$ and $\mathrm{C}=\mathrm{O}$ species, respectively. The $\mathrm{C} / \mathrm{O}$ ratio of $\mathrm{GO}$ is 1.73. After the reaction of GO with hemin under ultrasonication for $5 \mathrm{~h}$ at room temperature a significant decrease of the oxygen-bound carbons and $\mathrm{sp}^{3}$ carbon intensities was observed (Fig. 2A), suggesting the deoxygenation of the majority of oxygen-containing functional groups. In addition, the increase in intensity of the $\mathrm{sp}^{2}$ carbon peak at $283.6 \mathrm{eV}$ indicates that the distortion of the graphene conjugation induced upon oxidation in GO is restored. The $\mathrm{C} 1 \mathrm{~s}$ core level spectrum shows, next to the band at $283.6 \mathrm{eV}\left(\mathrm{sp}^{2}\right)$, contributions at $284.6(\mathrm{C}-\mathrm{C} / \mathrm{C}-\mathrm{H}), 286.4(\mathrm{C}-\mathrm{O}$, $\mathrm{C}-\mathrm{N}), 288.3(\mathrm{C}=\mathrm{O})$ and a small contribution at $290.1 \mathrm{eV}(\mathrm{O}-\mathrm{C}=$ $\mathrm{O}, 2.7 \%)$.

The incorporation of hemin into the rGO matrix is further evidenced by the presence of the Fe2p band (2.3\%) at $710.16 \mathrm{eV}$ $\left(\mathrm{Fe} 2 \mathrm{p}_{3 / 2}\right)$ and $723.16 \mathrm{eV}\left(\mathrm{Fe} 2 \mathrm{p}_{1 / 2}\right)$ (Fig. 2B) and of the N1s band $(8.3 \%)$ at $398 \mathrm{eV}$. While the binding energy of Fe $2 \mathrm{p}$ in hemin is reported to be $712.5\left(\mathrm{Fe} 2 \mathrm{p}_{3 / 2}\right)$ and $726.3 \mathrm{eV}\left(\mathrm{Fe} 2 \mathrm{p}_{1 / 2}\right),{ }^{47}$ in the case of hemin supported on $\mathrm{rGO}$ a pronounced shift by $\approx 2.3 \mathrm{eV}$ in binding energy is observed which suggests strong interaction between hemin and the rGO matrix. A similar effect is seen in the case of the position of the N1s peak, where binding energy shifts negatively from 401.8 (hemin) to $397.6 \mathrm{eV}$ after hemin is supported on rGO (Fig. 2C). ${ }^{47}$

The UV/Vis absorption spectra of GO, rGO/hemin and hemin are displayed in Fig. 3A. A dispersion of GO in water exhibits a maximum absorption at $226 \mathrm{~nm}$, attributed to the $\pi-\pi^{*}$ transition resulting from $\mathrm{C}=\mathrm{C}$ bonds of the aromatic skeleton. A broad shoulder around $297 \mathrm{~nm}$ corresponds to the $\mathrm{n}-\pi^{*}$ transition of $\mathrm{C}=\mathrm{O}$ bonds from carboxylic acid functions. The spectrum of hemin in methanol shows a strong absorption peak at $\approx 398 \mathrm{~nm}$ attributed to the Soret band, as well as a group for weak peaks between 450 and $650 \mathrm{~nm}$ ascribed to the Q-bands. The UV/Vis spectrum of $\mathrm{rGO} /$ hemin nanocomposites dispersed in water displays a broad absorption band at $265 \mathrm{~nm}$. The red shift from $226 \mathrm{~nm}$ (GO) to $265 \mathrm{~nm}$ for $\mathrm{rGO} /$ hemin is consistent with the restoration of the $\mathrm{sp}^{2}$ structure in rGO. An additional broad absorption below and above $400 \mathrm{~nm}$ is observed due to the ring $\pi \rightarrow \pi^{*}$ transitions of the Soret band of incorporated hemin. As the Soret band is sensitive to deformation of the ring in defect sites and/or ring stacking this might be an indication of a distribution of microenvironments within the rGO network. ${ }^{48}$ 


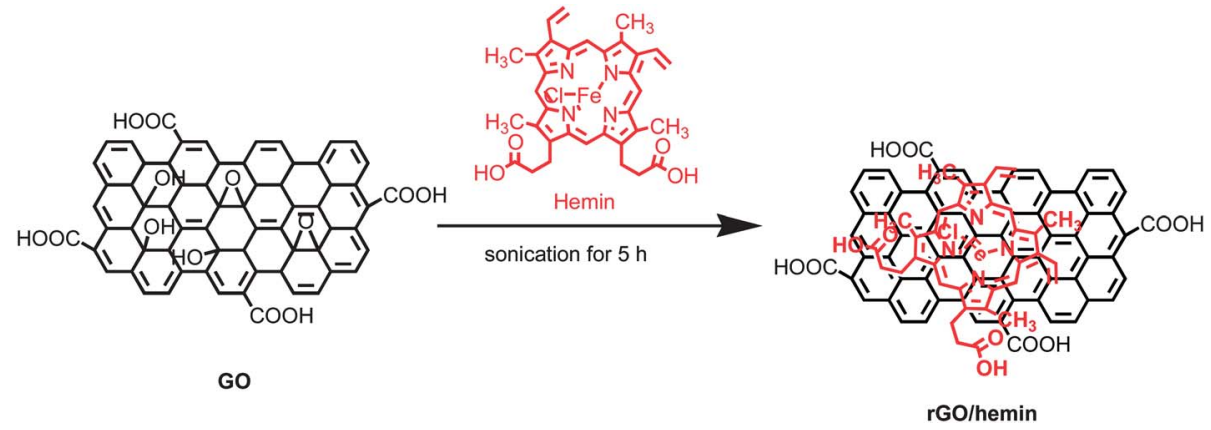

Fia 1 Schematic renresentation of the svnthesis of $\mathrm{rGO} /$ hemin

Raman scattering is a useful tool to characterize the structural properties of graphene-based materials. Fig. 3B shows the Raman spectra for $\mathrm{GO}$ and $\mathrm{rGO} /$ hemin presenting the main features of graphene-based materials: a D-band at $1351 \mathrm{~cm}^{-1}$, a G-band at $1570 \mathrm{~cm}^{-1}$ and a $2 \mathrm{D}$-band at $\approx 2700 \mathrm{~cm}^{-1}$. ${ }^{49}$ The D-band is usually ascribed to the destruction of the $\mathrm{sp}^{2}$ character and defects in the graphene sheets. The ratio of the intensities of the D and G bands $\left(I_{\mathrm{D}} / I_{\mathrm{G}}\right)$ can be used to monitor the degree of chemical modification of graphene. We found this ratio to be 0.71 for $\mathrm{GO}$ and 0.25 for $\mathrm{rGO} / \mathrm{hemin}$. This ratio is rather low compared to other reported values for $\mathrm{rGO}$ formed by other reducing agents such as hydrazine $\left(I_{\mathrm{D}} / I_{\mathrm{G}}=1.63\right),{ }^{50}$ sodium borohydride $\left(I_{\mathrm{D}} / I_{\mathrm{G}}>1.0\right)^{51}$ or Fe/ $\mathrm{HCl}\left(I_{\mathrm{D}} / I_{\mathrm{G}}=0.32\right)^{52}$ suggesting that $\mathrm{rGO} /$ hemin has little defects. It is also smaller than that recently reported by Vernekar $\left(I_{\mathrm{D}} / I_{\mathrm{G}}=1.06\right)$ claiming $\mathrm{rGO} /$ hemin formed from GO by using dithiothreitol as a reducing agent, which was then mixed with hemin under basic conditions. ${ }^{35}$ The position and shape of the $2 \mathrm{D}$ peak allows identification of single-layer, bi-layer and few-layered graphene. ${ }^{53,54}$ Indeed, the line shape of the $2 \mathrm{D}$ band of single-layer graphene is unique compared to the others and reflects the electronic band structure of graphene. It has a single Lorentzian line shape and a high intensity. As the number of graphene layers increases beyond two layers, the electronic band structure varies and approaches that of graphite. ${ }^{55,56} \mathrm{As}$ a result, the line shape of the 2D band also approaches that of graphite. In our case, the 2D band indicates that more than 5 graphene layers are deposited using the drop casting method. This is consistent with SEM investigations, where a film thickness of about $250 \mathrm{~nm}$ is obtained using the drop casting process.

\section{Electrochemical characteristics of $\mathrm{rGO} / \mathrm{hemin}$ films}

Cyclic voltammetry was used to study the electrochemical behavior of the rGO/hemin matrix. Glassy carbon electrodes (GCEs) were modified with the $\mathrm{rGO} /$ hemin nanocomposites ( $0.5 \mathrm{mg} \mathrm{mL} \mathrm{m}^{-1}$ in DMF) by drop-casting, widely employed for the formation of graphene-based electrodes given the simplicity of the approach. ${ }^{57}$ The thickness of the $\mathrm{rGO} / \mathrm{hemin}$ matrix was determined by scanning electron microscopy (SEM) to be about $250 \pm 20 \mathrm{~nm}$ (5 different electrodes tested), which indicates that the method of manufacturing is fairly reproducible. Fig. 4 shows cyclic voltammograms recorded at a bare glassy carbon electrode (GCE) and after modification with $\mathrm{rGO}$ /
(A)

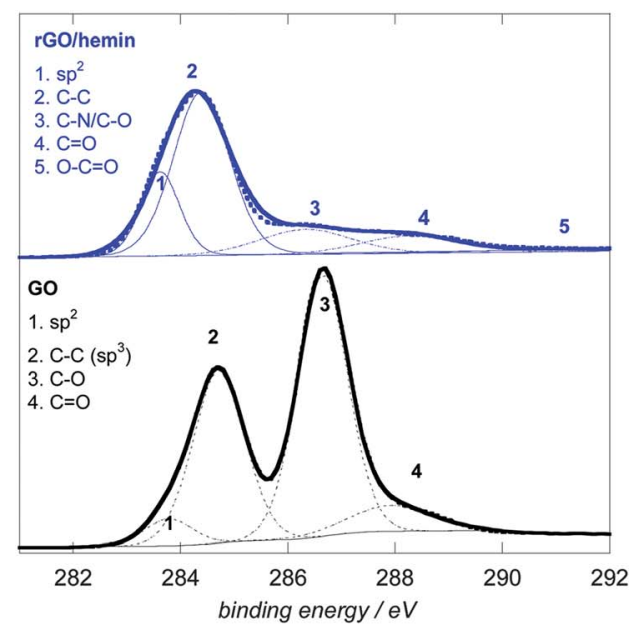

(B)

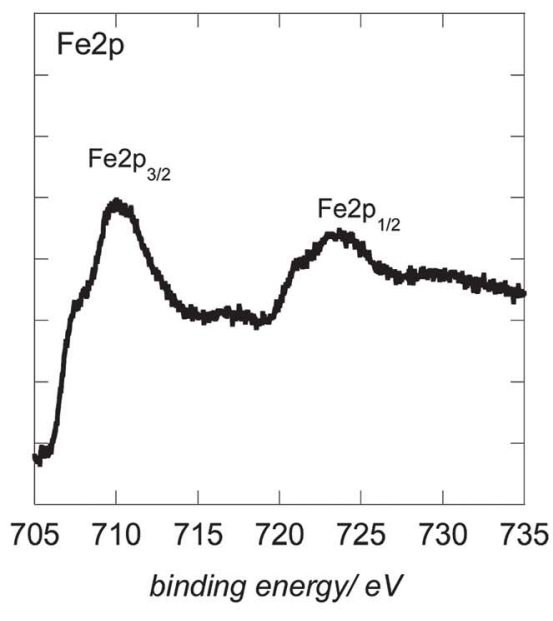

(C)

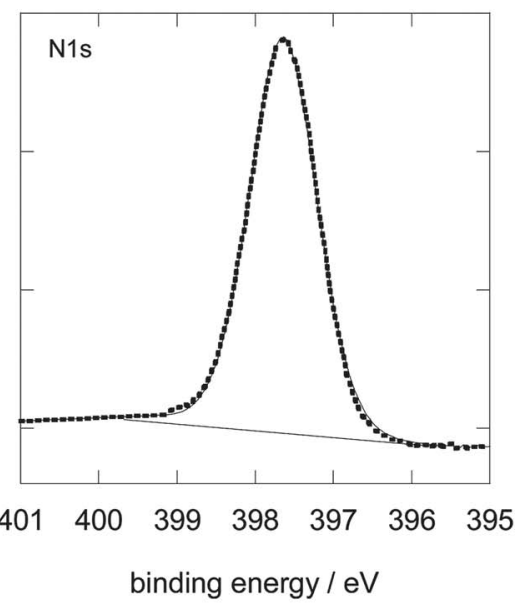

Fig. 2 High resolution XPS spectra: (A) C1s of GO (black) and rGO/hemin (blue), (B) Fe2p of rGO/hemin, and (C) N1s of rGO/hemin. 
(A)

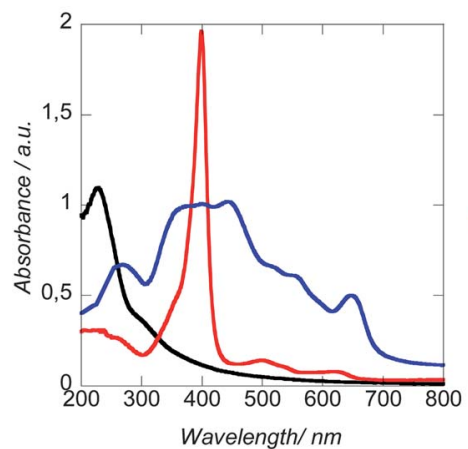

(B)

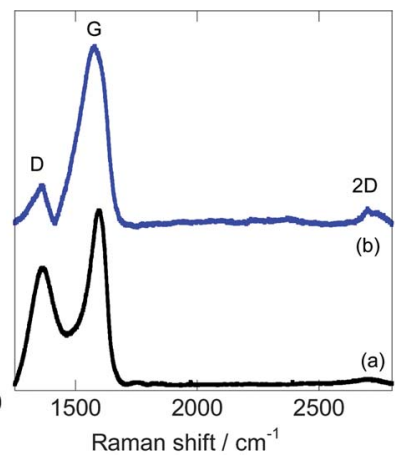

Fig. 3 (A) UV/Vis spectra of an aqueous solution of GO in water (black), hemin solution in methanol (red) and of $\mathrm{rGO} /$ hemin in water (blue); (B) Raman spectra of $\mathrm{GO}$ (black) and $\mathrm{rGO} /$ hemin (blue).

hemin. As expected, in the absence of $\mathrm{rGO} /$ hemin, no redox peaks were observed in the potential range investigated. By contrast, GCE coated with $\mathrm{rGO} /$ hemin exhibits a stable redox peak at about $E=0.4 \mathrm{~V}$ that is attributed to the $\mathrm{Fe}^{3+/ 2+}$ center of hemin..$^{31,34,58}$ The amount of hemin $(T)$ incorporated into the rGO matrix was estimated by integrating the anodic peak area according to $T=Q / n F A$ where $F$ is the Faraday constant, $n$ is the number of electrons exchanged $(n=1)$ and $A$ is the surface area. As the active surface area will be larger than the geometric area of the interface cyclic voltammetric measurements in $10 \mathrm{mM} \mathrm{Fe}(\mathrm{CN})_{6}{ }^{4-}$ solutions using a GCE interface coated with $\mathrm{rGO} /$ hemin by drop casting were performed and a surface area of $A=0.47 \mathrm{~cm}^{2}$ was determined. The active surface area found is obviously much larger than the geometric one of $0.19 \mathrm{~cm}^{2}$. The average surface coverage of electroactive hemin in the rGO matrix estimated on 5 different electrodes using the same $\mathrm{rGO} /$ hemin nanocomposites and on 5 different electrodes using $\mathrm{rGO} /$ hemin nanocomposites prepared in a second batch was $\Gamma=(3.6 \pm 0.5) \times 10^{-8} \mathrm{~mol} \mathrm{~cm}^{-2}$. This value is much larger than that reported for hemin-pyrolytic graphite $\left(\Gamma=74.5 \times 10^{-10} \mathrm{~mol} \mathrm{~cm}{ }^{-2}\right),{ }^{59}$ hemin-multiwalled carbon nanotubes $\left(\Gamma=2.70 \times 10^{-9} \mathrm{~mol} \mathrm{~cm}^{-2}\right)^{60}$ and is comparable to hemin immobilized on highly ordered mesoporous carbon $\left(\Gamma=1.74 \times 10^{-8} \mathrm{~mol} \mathrm{~cm}^{-2}\right){ }^{61}$ The high loading of hemin on rGO indicates the high preferential binding of hemin by $\pi-\pi$ stacking interactions with rGO. The anodic part of the cyclic voltammogram of $\mathrm{rGO} /$ hemin shows an irreversible wave at about $E=+0.95 \mathrm{~V} v s$. $\mathrm{Ag} / \mathrm{AgCl}$ assigned to ring oxidation of the pyrrole macrocycle in hemin to its radical-cation. ${ }^{62}$ The hemin loading of this novel $\mathrm{rGO} /$ hemin composite material is indeed exceptionally high. In comparison, a GCE electrode modified by drop casting with $\mathrm{rGO}$ formed by reduction of GO with hydrazine followed by immersion of the GCE-rGO interface into $0.5 \mathrm{mM}$ hemin for $5 \mathrm{~h}$ to incorporate hemin into the graphene network through $\pi-\pi$ and cation $-\pi$ interactions resulted in a hemin coverage of $\Gamma=(1.4 \pm 0.5) \times$ $10^{-8} \mathrm{~mol} \mathrm{~cm}^{-2}$, which is 2.5 times lower than that obtained by the direct reaction of hemin with GO under ultrasonication (Fig. 4).

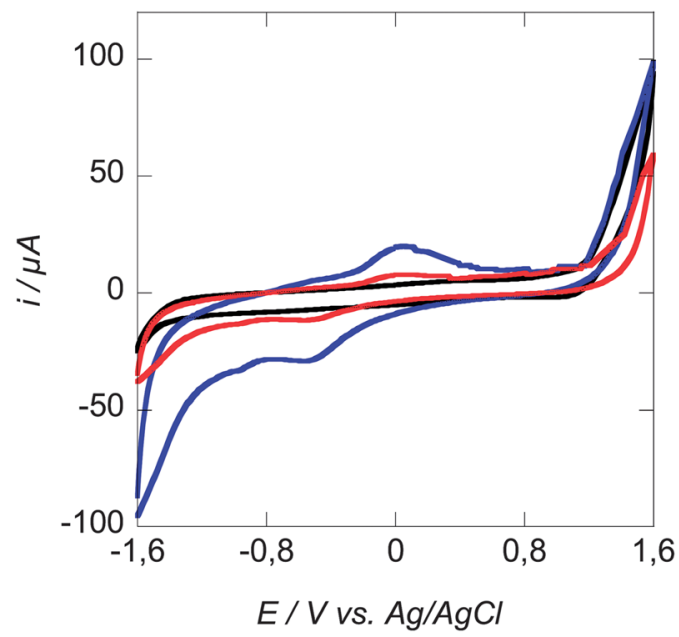

Fig. 4 Cyclic voltammograms of a bare glassy carbon (black), rGO/hemin modified GCE electrode prepared by drop casting $100 \mu \mathrm{L}$ of $\mathrm{rGO} /$ hemin $(0.5$ $\mathrm{mg} \mathrm{mL}{ }^{1}$ ) onto GCE (blue), and GCE modified by drop casting of $100 \mu \mathrm{L} \mathrm{rGO}$ (reduction with hydrazine) immersed for $12 \mathrm{~h}$ into hemin solution $(0.5 \mathrm{mM})(\mathrm{red})$ : solution: $\mathrm{N}_{2}$ saturated PBS buffer $(0.1 \mathrm{M}, \mathrm{pH} 7.4)$, scan rate: $50 \mathrm{mV} \mathrm{s}{ }^{1}$.

\section{Electrochemical investigation of the peroxynitrite activity of $\mathbf{r G O} / \mathrm{hemin}$ films}

The performance of the $\mathrm{rGO} /$ hemin modified GCE towards the detection of peroxynitrite was evaluated by chronoamperometry using the sydnonimine SIN-1 as peroxynitrite producer (Fig. 5A). While fairly stable in alkaline solutions, peroxynitrite readily decomposes $(<1 \mathrm{~s})$ in physiological buffers mainly through the isomerisation of its conjugated acid ONOOH.$^{63}$ Voltammetric studies under neutral conditions have thus been proven to be difficult and are mainly performed under basic conditions. ${ }^{27,64}$ The use of donor solutions of SIN-1 has thus become widely accepted as one way to overcome this limitation. ${ }^{28}$ SIN-1 liberates superoxide anions $\left(\mathrm{O}_{2}^{-}\right)$and nitric oxide (NO) spontaneously in solution with a $1: 1$ stoichiometry, thereby generating $\mathrm{ONOO}^{-}$continuously for a certain period of time (Fig. 5A). ${ }^{45}$ Indeed, in an aerobic aqueous solution SIN-1 decomposes readily to SIN-1A, which in the presence of an oxidant like oxygen forms the unstable SIN-1A radical cation. The latter liberates NO and eventually forms the stable end product 3-morpholinoiminoacetonitrile (SIN-1C).

The performance of the $\mathrm{rGO} /$ hemin modified GCE towards the detection of peroxynitrite was evaluated by chronoamperometry using parameters determined from the cyclic voltammetry investigation. Addition of $\mathrm{ONOO}^{-}$, generated from SIN-1, to a GCE/rGO/hemin electrode shows an oxidative wave at $E_{\text {ox }, 1}=1.17 \mathrm{~V}$ (Fig. 5B). This wave is close to the oxidation potential of hemin and is thus assigned to the electrochemical oxidation of hemin on the rGO platform. In the presence of $\mathrm{ONOO}^{-}$, an electrocatalytic oxidation $\mathrm{ONOO}^{-}$mediated by oxidized hemin centers seems to occur (Fig. 5C). ${ }^{65} \mathrm{The}^{\mathrm{Fe}^{3+}}$ center in the $\mathrm{rGO} / \mathrm{hemin}$ film is oxidized to a high valent iron form (e.g. iron oxo intermediate, $\left[\mathrm{Fe}^{4+}=\mathrm{O}\right]$ ) electrochemically at the electrode interface, which, in the presence $\mathrm{ONOO}^{-}$, is re-reduced back to $\mathrm{Fe}^{3+}$ for further turnovers. 
(A)

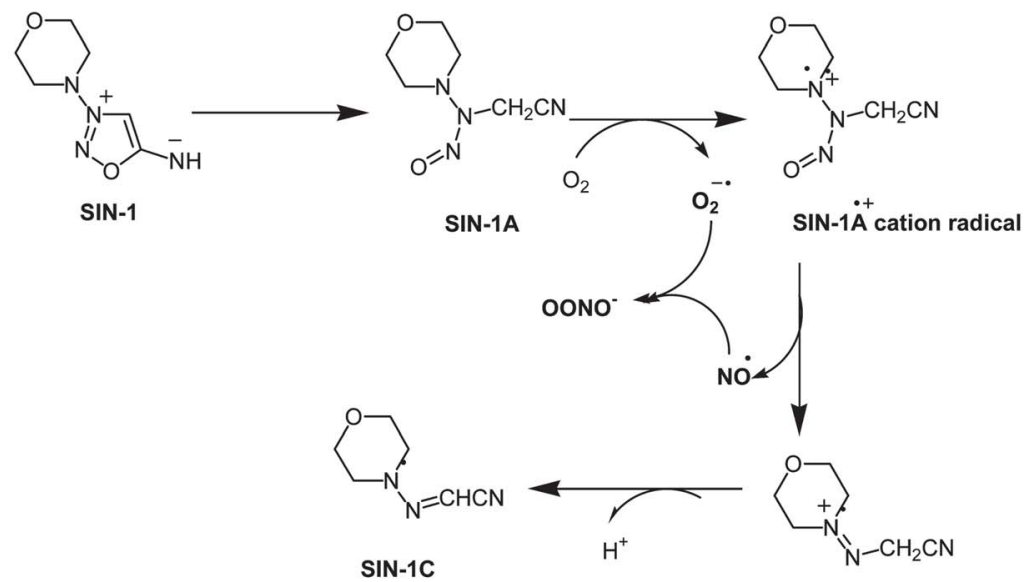

(B)

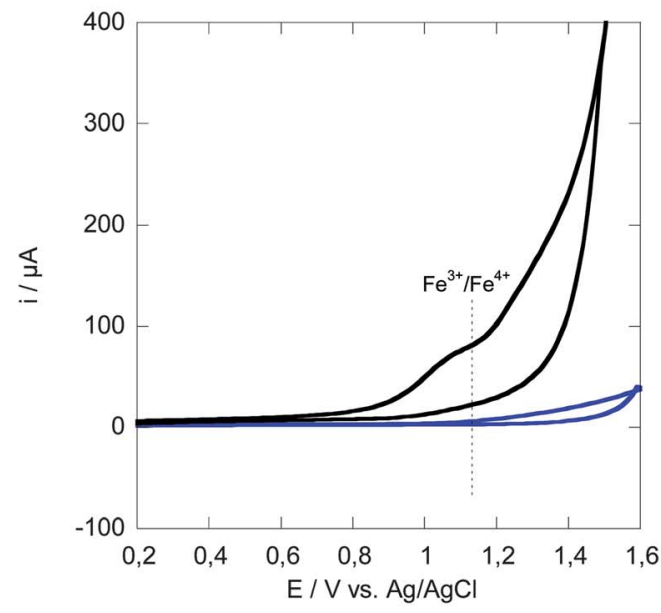

(C)

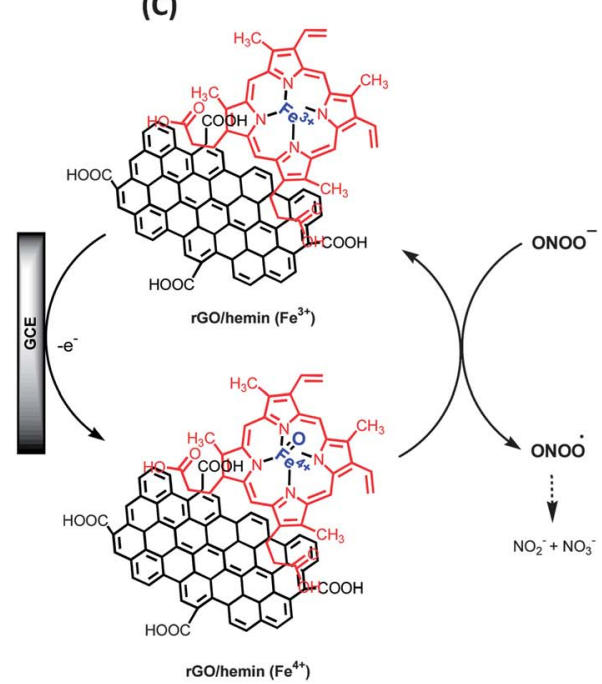

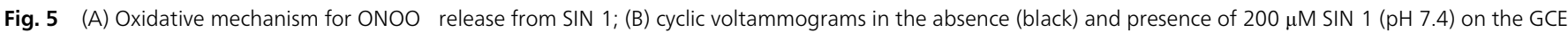

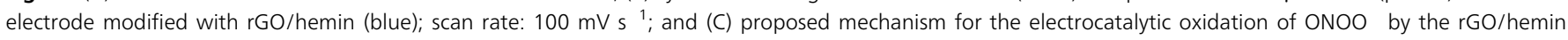
interface.

The electrocatalytic reaction between hemin and $\mathrm{ONOO}^{-}$ occurring at $E_{\mathrm{ox}, 1}=1.17 \mathrm{~V}$ was used in the following for the sensitive detection of $\mathrm{ONOO}^{-}$(Fig. 6A). As can be seen from the calibration curve in Fig. $6 \mathrm{~B}$ the oxidation current scales linearly with increasing $\mathrm{ONOO}^{-}$concentrations. From the slope of the calibration curve, the sensitivity of the $\mathrm{GCE} / \mathrm{rGO} / \mathrm{hemin}$ electrode towards peroxynitrite was evaluated to be $\approx 7.5 \pm 1.5 \mathrm{nA} \mathrm{nM}^{-1}$. The limit of detection (LOD), expressed as the concentration derived from the smallest measure that can be detected with reasonable certainty, was determined to be $\approx 5 \mathrm{nM}$ with a relative standard deviation under optimal conditions of less than $5 \%$ for 7 samples measured. The detection limit is one of the lowest so far reported for peroxynitrite sensors. Manganese tetraaminophthalocyanine modified platinum or $\mathrm{Pt} / \mathrm{C}$ microelectrodes showed a LOD $=5 \mu \mathrm{M}$ (ref. 64) and $20 \mathrm{nM}$, respectively. ${ }^{23} \mathrm{In}$ addition, the LOD determined for peroxynitrite on the GCE/rGO/ hemin electrode is lower than that recently reported for nanostructured polymerized EDOT/hemin carbon fiber microelectrodes $(\mathrm{LOD}=200 \mathrm{nM})^{27}$ and poly(cyanocobalamin)-modified
GCE $(\mathrm{LOD}=100 \mathrm{nM}) \cdot{ }^{29}$ The in situ hemin functionalization of rGO as described in this work is crucial for achieving the relatively high sensitivity and low detection limit for $\mathrm{GCE} / \mathrm{rGO} / \mathrm{hemin}$ electrodes. In fact, electrodes modified with rGO purified from a hydrazine-driven reduction process of $\mathrm{GO}$, and immersed in hemin solution for a period as long as 5 hours, do not reproduce the sensitivity and detection limit observed for electrodes modified with the "one-pot" rGO/hemin material. Fig. 6B shows that hemin-treated rGO-modified electrodes have a significantly low sensitivity compared to $\mathrm{rGO} /$ hemin electrodes $\left(0.6 \mathrm{nA} \mathrm{nM}{ }^{-1}\right.$ versus $5 \mathrm{nA} \mathrm{nM}^{-1}$ ). Also, their detection limit is relatively higher (11 nM). The amount of hemin incorporated onto the electrode seems to be crucial for the sensitive detection of peroxynitrite. The amount of hemin incorporated into the chemically formed $\mathrm{rGO} /$ hemin matrix is 2.5 times larger than that on rGO postmodified with hemin. The higher hemin loading in the "one-pot" preparation of the $\mathrm{rGO} /$ hemin material is probably facilitated by the large surface area provided by GO during the reduction process under ultrasonication in the presence of hemin. 
(A)

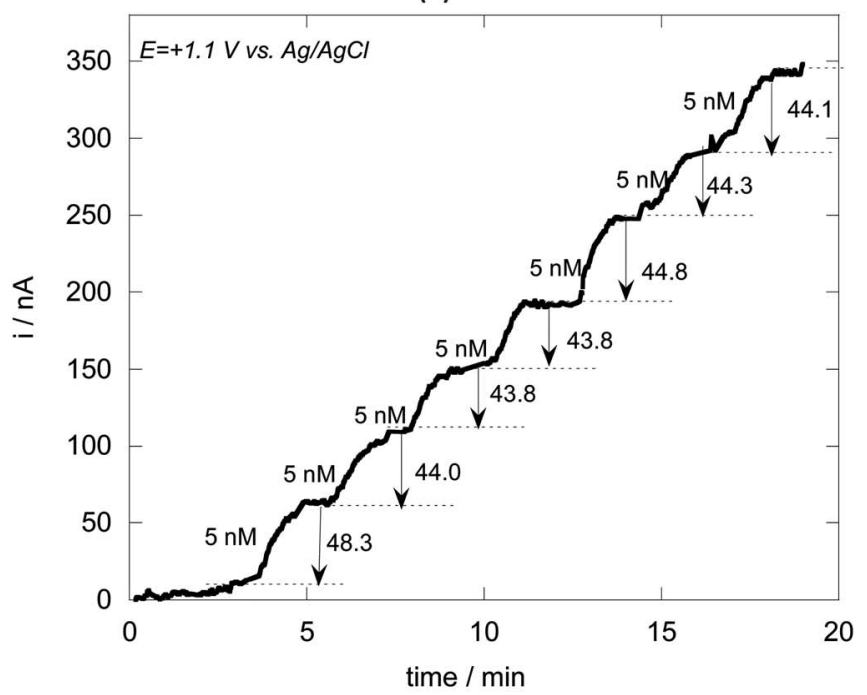

(B)

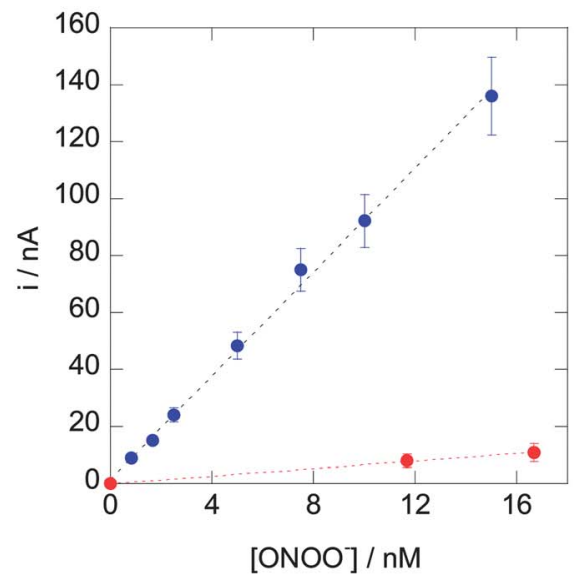

Fig. 6 (A) Typical amperometric response curve obtained using a GCE/rGO/ hemin electrode polarized at $+1.1 \mathrm{~V} v$ s. Ag/AgCl with subsequent addition of SIN 1. (B) Calibration curve of $\mathrm{rGO} /$ hemin modified GCE $(\bullet)$ and $\mathrm{rGO}$ modified GCE after immersion into hemin solutions (๑).

\section{Conclusion}

In conclusion, we have demonstrated in this paper that rGOhemin conjugates can be easily prepared by simple mixing of GO with hemin and ultrasonicating the mixture for $5 \mathrm{~h}$ at $50{ }^{\circ} \mathrm{C}$ without the use of any additional reducing agent or base. The obtained rGO/hemin nanocomposite was highly stable and tested as a sensitive platform for peroxynitrite detection in neutral $\mathrm{pH}$. We showed that the sensitivity of the $\mathrm{rGO} /$ heminmodified electrodes for peroxynitrite was $\approx 7.5 \pm 1.5 \mathrm{nA} \mathrm{nM}^{-1}$ with a low nanomolar detection limit of $\approx 5 \pm 1 \mathrm{nM}$. For comparison, the sensitivity of rGO formed by hydrazine reduction and post-modified with hemin was almost an order of magnitude lower at $\sim 0.6 \mathrm{nA} \mathrm{nM}^{-1}$ and at a detection limit of $11 \mathrm{nM}$. The fundamental reasons for such an enhancement are diverse and need to be investigated in the future. In general, several combined features of the graphene support may contribute to the enhanced performance. Firstly, graphene provides a two-dimensional support with large open and accessible surface area where the diffusion of peroxynitrite is much easier, which could be beneficial for the surface-driven electrocatalytic activity. Secondly, graphene-supported hemin could prevent hemin molecules from self-polymerization (or $\pi-\pi$ stacking) and thus increase the available active sites. Thirdly, the amount of hemin present on the electrodes seems to be crucial. The amount of hemin incorporated into the new $\mathrm{rGO} /$ hemin matrix is 2.5 times larger than that on rGO post-modified with hemin. While additional work is needed to shed more light on the catalytic mechanism at play, the study clearly highlights the importance of the use of graphene supported hemin as a general strategy for the fabrication of highly sensitive peroxynitrite sensors. Efforts to transfer graphene-hemin to micrometric electrodes are currently under way.

\section{Acknowledgements}

R.B. and S.S. gratefully acknowledge financial support from the Centre National de Recherche Scientifique (CNRS), the University Lille 1 and Nord Pas de Calais region. R.O. thanks the University Lille 1 for the scientific scholarship to carry out her Master project. S.S. thanks the Institut Universitaire de France (IUF) for financial support. S.F.P. and R.O. acknowledge the Agentia Nationala de Cercetare Stiintifica (ANCS-UEFISCDI) for the PN-II project 184/2011. M.B. acknowledges funding by The National Science Foundation (to MB, Grant CHE-0848820), by an FRD grant from Ohio Board of Regents, and by funds from Cleveland State University.

\section{References}

1 W. H. Koppenol, J. J. Moreno, W. A. Pryor, H. Ischiropoulos and J. S. Beckman, Chem. Res. Toxicol., 1992, 5, 834.

2 G. Ferrer-Sueta and R. Radi, ACS Chem. Biol., 2009, 4, 161.

3 C. Amatore, S. Arbault, C. Bouton, J. C. Drapier, H. Ghandour and A. C. W. Koh, ChemBioChem, 2008, 9, 1472.

4 S. F. Peteu, M. S. Banihani, M. M. Gunesekera, P. Peiris, O. A. Sicuia and M. Bayachou, Peroxynitrite and nitroxidative stress: detection probes and micro-sensors. A case of a nanostructured catalytic film, oxidative stress and antioxidants: diagnosis and therapy, in oxidative Stress: Diagnostics, Prevention, and Therapy, American Chemical Society Symposium Series, vol. 1083, 2011, ch. 11, pp. 311-339.

5 S. Borgmann, Anal. Bioanal. Chem., 2009, 394, 95-105.

6 D. Quinton, S. Griveau and F. Bedioui, Electrochem. Commun., 2010, 12, 1446-1449.

7 M. M. Tarpey and I. Fridovich, Circ. Res., 2001, 89, 224-236.

8 G. Ferrer-Sueta and R. Radi, ACS Chem. Biol., 2009, 4, 161177.

9 P. T. Liu, C. E. Hock, R. Nagele and P. Y. K. Wong, Am. J. Physiol.: Heart Circ. Physiol., 1997, 272, H2327-H2336.

10 C. Szabo, H. Ischiropoulos and R. Radi, Nat. Rev. Drug Discovery, 2007, 6, 662-680.

11 R. Radi, J. S. Beckman, K. M. Bush and B. A. Freeman, Arch. Biochem. Biophys., 1991, 288, 481-487.

12 Z. N. Sun, H. L. Wang, F. Q. Liu, Y. Chen, P. K. H. Tam and D. Yang, Org. Lett., 2009, 11, 1887-1890. 
13 P. Panizzi, M. Nahrendorf, M. Wildgruber, P. Waterman, J. L. Figueiredo, E. Aikawa, J. McCarthy, R. Weissleder and S. A. Hilderbrand, J. Am. Chem. Soc., 2009, 131, 15739-15744. 14 D. Yang, H. L. Wang, Z. N. Sun, N. W. Chung and J. G. Shen, J. Am. Chem. Soc., 2006, 128, 6004.

15 J. C. Huang, D. J. Li, J. C. Diao, J. Hou, J. L. Yuan and G. L. Zou, Talanta, 2007, 72, 1283-1287.

16 F. J. Martin-Romero, Y. Gutierrez-Martin, F. Henao and C. Gutierrez-Merino, J. Fluoresc., 2004, 14, 17.

17 B. J. Privett, J.-H. Shin and M. H. Schoenfish, Chem. Soc. Rev., 2010, 39, 1925.

18 C. Amatore, S. Arbault, M. Guille and F. Lemaitre, Chem. Rev., 2008, 108, 2585.

19 F. Bedioui, D. Quninton, S. Griveau and T. Nyokong, Phys. Chem. Chem. Phys., 2010, 12, 9976.

20 C. Amatore, S. Arbault, D. Bruce, P. De Oliveira, M. Erard and M. Vuillaume, Chem.-Eur. J., 2001, 7, 4171.

21 C. Amatore, S. Arbault, C. Bouton, K. Coffi, J. C. Drapier, H. Ghandour and Y. Tong, ChemBioChem, 2006, 7, 653661.

22 C. Amatore, S. Arbault, D. Bruce, P. De Oliveira, M. Erard and M. Vuillaume, Faraday Discuss., 2000, 116, 319.

23 J. Xue, X. Ying, J. Chen, Y. Xian, L. Jin and J. Jin, Anal. Chem., 2000, 72, 5313-5321.

24 R. Kubant, C. Malinski, A. Burewicz and T. Malinski, Electroanalysis, 2006, 18, 410.

25 D. Quinton, A. Girard, L. T. T. Kim, V. Raimbault, L. Griscom, F. Razan, S. Griveau and F. Bedioui, Lab Chip, 2011, 11, 1342.

26 J. Sandoval Cortes, S. Gutierrez Grabados, A. Alatorre, J. A. Lopez Jiminez, S. Griveau and F. Bedioui, Electroanalysis, 2007, 19, 61.

27 S. Peteu, P. Peiris, E. Gebremichael and M. B. Bayachou, Biosens. Bioelectron., 2010, 25, 1914-1921.

28 W. C. A. Koh, J. I. Son, E. S. Choe and Y.-B. Shim, Anal. Chem., 2010, 82, 10075.

29 T. Xue, S. Jiang, Y. Qu, Q. Su, R. Cheng, S. Dubin, C.-Y. Chiu, R. B. Kaner, Y. Huang and X. Duan, Angew. Chem., Int. Ed., 2012, 51, 3822.

30 P. V. Kamat, J. Phys. Chem. Lett., 2010, 1, 520.

31 Y. Guo, J. Li and S. Dong, Sens. Actuators, B, 2011, 160, 295.

32 C. X. Guo, Y. Lei and C. M. Li, Electroanalysis, 2011, 23, 885.

33 C. Xu, J. Li, X. Wang, J. Wang, L. Wan, Y. Li, M. Zhang,

X. Shang and Y. Yang, Mater. Chem. Phys., 2012, 132, 858.

34 Y. Guo, L. Deng, J. Li, S. Guo, E. Wang and S. Dong, ACS Nano, 2011, 5, 1282.

35 A. A. Vernekar and G. Mugesh, Chem.-Eur. J., 2012, 18, 15122-15132.

36 I. Kaminska, A. Barras, Y. Coffinier, W. Lisowski, J. Niedziolka-Jonsson, P. Woisel, J. Lyskawa, M. Opallo, A. Siriwardena, R. Boukherroub and S. Szunerits, ACS Appl. Mater. Interfaces, 2012, 4, 5386.

37 I. Kaminska, M. R. Das, Y. Coffinier, J. Niedziolka-Jonsson, J. Sobczak, P. Woisel, J. Lyskawa, M. Opallo, R. Boukherroub and S. Szunerits, ACS Appl. Mater. Interfaces, 2012, 4, 1016.

38 I. Kaminska, M. R. Das, Y. Coffinier, J. Niedziolka-Jonsson, P. Woisel, M. Opallo, S. Szunerits and R. Boukherroub, Chem. Commun., 2012, 48, 1221.
39 L. Q. Xu, W. J. Yang, K.-G. Neoh, E.-T. Kang and G. D. Fu, Macromolecules, 2010, 43, 8336.

40 G. Yang, G. Zhang, P. Sheng, F. Sun, W. Wu and D. Zhang, J. Mater. Chem., 2012, 22, 4391.

41 W. S. Hummers and J. R. E. Offerman, J. Am.Chem. Soc., 1958, 80, 1339.

42 M. R. Das, R. K. Sarma, R. Saikia, V. S. Kale, M. V. Shelke and P. Sengupta, Colloids Surf., B, 2011, 83, 16.

43 S. Stankovich, D. A. Dikin, R. D. Piner, K. A. Kohlhaas, A. Kleinhammes, Y. Jia, Y. Wu, S. T. Nguyen and R. S. Ruoff, Carbon, 2007, 45, 1558-1565.

44 Y. Asahi, K. Shinozaki and M. Nagaka, Chem. Pharm. Bull., 1971, 19, 1079.

45 M. Feelisch, J. Ostrowski and E. Noack, J. Cardiovasc. Pharmacol., 1989, 14, 13.

46 D. S. Bohle, P. A. Glassbrenner and B. Hansert, Methods Enzymol., 1996, 269, 302-311.

47 Z.-X. Liang, H.-Y. Song and S.-J. Lia, J. Phys. Chem. C, 2011, 115, 2604.

48 Y. X. Xu, L. Zhao, H. Bai, W. J. Hong, C. Li and G. Q. Shi, J. Am. Chem. Soc., 2009, 131, 13490.

49 H. L. Wang, J. T. Robinson, X. L. Li and H. J. Dai, J. Am. Chem. Soc., 2009, 131, 9910.

50 J. Yan, Z. J. Fan, T. Wei, W. Z. Qian, M. Zhang and F. Wei, Carbon, 2010, 48, 3825.

51 H. J. Shin, K. K. Kim, A. Benayad, S. M. Yoon, H. K. Park, I. S. Jung, et al., Adv. Funct. Mater., 2009, 19, 1987.

52 Z. Fang, W. Kai, J. Yan, T. Wei, L.-J. Zhi, J. Feng, Y.-M. Ren, J.-P. Song and F. Wei, ACS Nano, 2011, 5, 191.

53 A. C. Ferrari, J. C. Meyer, V. Scardaci, C. Casiraghi, M. Lazzeri, F. Mauri, S. Piscanec, D. Jiang, K. S. Novoselov, S. Roth and A. K. Geim, Phys. Rev. Lett., 2006, 97, 187401.

54 D. Yoon and $\mathrm{H}$. Cheong, Raman Spectroscopy for Characterization of Graphene, Springer-Verlag, Berlin Heidelberg, 2012.

55 S. Latil and L. Henrard, Phys. Rev. Lett., 2006, 97, 036803.

56 R. Saito, G. Dresselhaus and M. S. Dresselhaus, J. Appl. Phys., 1993, 73, 494-500.

57 K. R. Ratinac, W. J. Yang, J. J. Gooding, P. Thordarson and F. Braet, Electroanalysis, 2011, 23, 803.

58 J. Wei, J. Qiu, L. Li, L. Ren, X. Zhang, J. Chaudhuri and S. Wang, Nanotechnology, 2012, 23, 335707.

59 J. Chen, U. Wollenberger, F. Lisdat, B. Ge and F. W. Scheller, Sens. Actuators, B, 2000, 70, 115.

60 J. S. Ye, Y. Wen, W. DeZhang, H. F. Cui, L. M. Gan, G. Q. Xu and F. S. Sheu, J. Electroanal. Chem., 2004, 562, 241.

61 H. Cao, X. Sun, Y. Zhang, C. Hu and N. Jia, Anal. Methods, 2012, 4, 2412.

62 J. N. Younathan, K. S. Wood and T. J. Meyer, Inorg. Chem., 1992, 31, 3280.

63 R. Kissner, T. Nauser, P. Bugnon, P. G. Lye and W. H. Koppenol, Chem. Res. Toxicol., 1997, 10, 1285.

64 J. S. Cortes, S. G. Granados, A. A. Ordaz, J. A. L. Jimenez, S. Griveau and F. Bedioui, Electroanalysis, 2007, 19, 6164.

65 S. F. Peteu, T. Bose and M. Bayachou, Anal. Chim. Acta, 2013, 780, 81-88. 